\title{
Multiple urethral anomalies: Parameatal urethral cyst, penile curvature, incomplete hypospadiac anterior duplication of the urethra and distal hipospadias
}

\author{
Devrim Tuglu, MD; Ercan Yuvanç, MD; Erdal Yılmaz, MD; Serhan Gur, MD; Ertan Batislam, MD \\ University of Kirikkale, Faculty of Medicine, Department of Urology, Kirikkale, Turkey
}

Cite as: Can Urol Assoc J 2015;9(5-6):E294-6. http://dx.doi.org/10.5489/cuai.2367

Published online May 13, 2015.

\section{Abstract}

The male genitourinary system is quite complex. There are numerous known anomalies of the male urethra either as isolated cases or in combination with other disorders. An improved understanding of the embryology and anatomy of the normal male urethral development might help explain the causes of the various urethral abnormalities. We contribute to the etiology of congenital anomalies with this multiple urethral anomalies case.

\section{Case report}

A 33-year-old male presented with a cystic lesion, situated at the external urethral meatus since birth. There were additional complaints of penile deviation and inability to void from the tip of the penis. On physical examination of the penis, we found two external urethral meatus located on the subcoronal and mid-penile hypospadias region in the proximal part. We also found the subcoronal meatus was 3 to $4 \mathrm{~cm}$ in length and blind ended; the other mid-penile urethra was open. In addition, a 9-mm diameter spherical cystic soft mass protruded outward from the edge of the left side of the external urethral meatus. A 40 to $50^{\circ}$ dorsal penile deviation was found upon evaluating the patient's photo of the penis (Fig. 1). There were no urinary symptoms other than spraying of the downward urinary stream and poor cosmesis. The patient had no history of trauma, sexually transmitted diseases, or circumcision. No inflammatory signs were present. His blood counts, blood chemistry, urine analysis, and urine culture were normal.

The patient had multiple anomalies, such as parameatal cyst, urethral duplication, mid-penile hypospadias, and penile chordee. We performed a parameatal cyst excision and a duplicated urethra repair, then the hypospadias was repaired by a tubularized incised plate urethroplasty and the finally penile plication was done. The patient was discharged on postoperative day 1 . A histopathological examination of the parameatal cyst wall revealed an outer surface covered by ceratinized stratified squamous epithelium and an inner surface of the dermis lined by pseudostratified columnar and squamous epithelium No inflammatory and malignancy signs were present. Postoperative follow-up at 15 days and 3 and 6 months were normal. Good cosmetic results were obtained, without meatal strictures, penil deviation, cyst recurrence, and urine flow problems.

\section{Discussion}

Urethral duplication is an extremely rare congenital malformation, but various clinical manifestations and treatments have been well-defined. ${ }^{1}$ Several types of anatomic variations have been identified with the accessory urethra, being complete or incomplete, epispadic, hypospadic, normotopic or perineoanal. Urethral duplication is often linked to other anomalies. ${ }^{2,3}$

The embryology is unclear; however, several embryological theories have been suggested. Casselman and Williams $\mathrm{s}^{4}$ indicated that a partial failure or an irregularity of the ingrowth of the lateral mesoderm between the ectodermal and layers of the cloacal membrane in the midline accounts for the forms with a dorsal epispadiac channel. Das and Brosman ${ }^{5}$ reported that the abnormal termination of the müllarian duct was responsible for urethral duplication. Rica and colleagues ${ }^{6}$ stated that asymmetry in the closure of the urorectal septum results in an urethraperineal fistula.

Urethral duplication can be classified into three types using Effmann's classification (Fig. 2). ${ }^{7}$ In our case, the urethral meatus did not end at the glans and therefore does not fit in this classification; the only structural similarity to the Type I duplication is the partial duplication. The meatus 


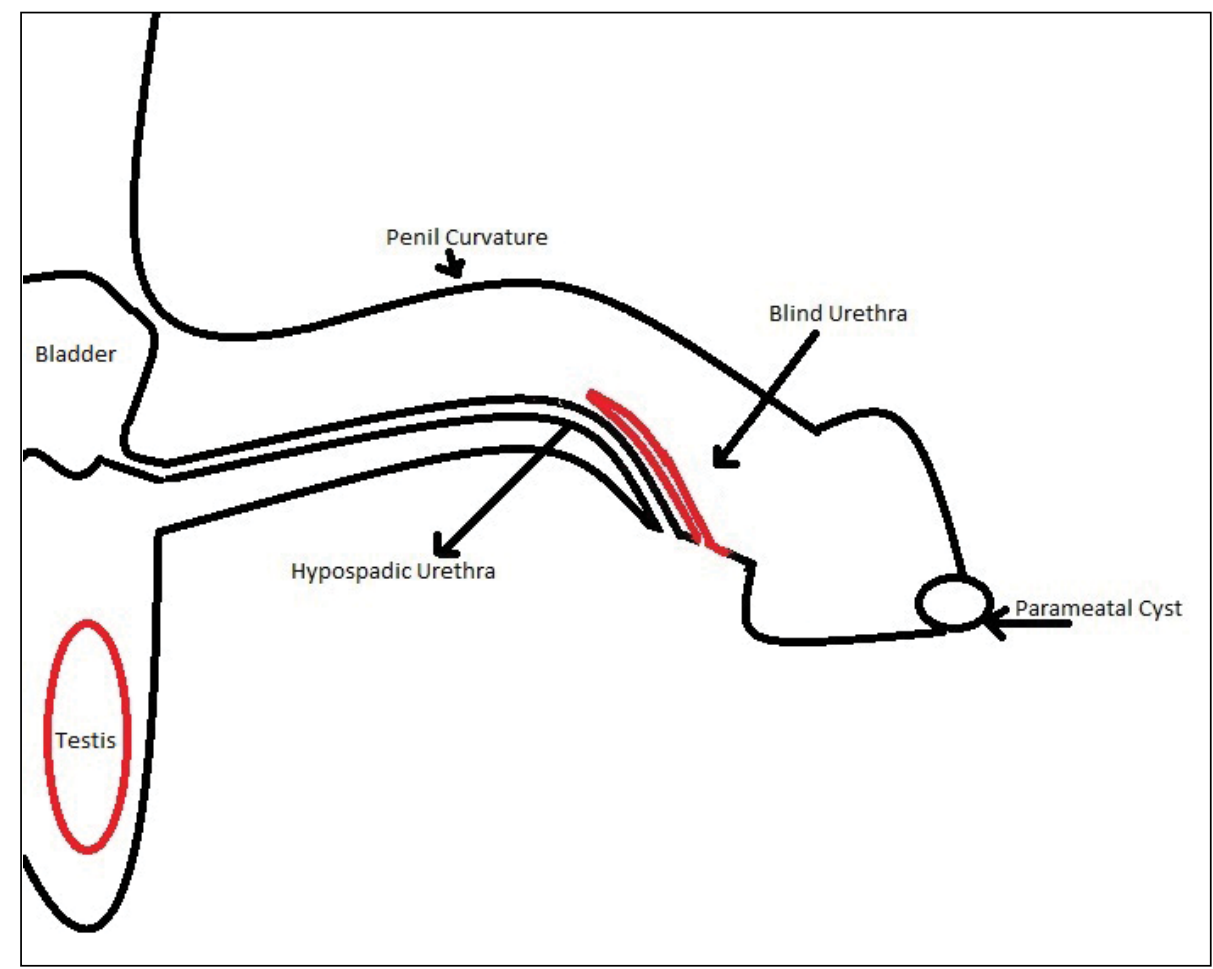

Fig. 1. Illustration of the urethral anomalies of our case.

completely opened in the part of the spongiosum and was ventrally located (Fig. 3).

Parameatal urethral cysts are very rare benign lesions seen in boys, but they can also occur in infants, girls, and adults. They were first described by Thompson and Lantin ${ }^{8}$ in 1956 and nearly 50 cases have been published since. The pathogenesis of these cysts has not been exactly understood. Thompson and Lantin indicated that parameatal urethral cysts occurred in the process of delamination or separation of the foreskin from the glans penis, while Yoshida ${ }^{9}$ believed that they were caused by occlusions of paraurethral ducts. Hill and colleagues ${ }^{10}$ suggested that these obstructions could be caused by infections. Recently, Soyer and colleagues ${ }^{11}$ reported two cases of newborns, in whom paraurethral cysts were associated with vaginal bleeding and breast enlargement; these factors showed the possibility of the role of estrogens in their development. The origin of parameatal urethral cysts from accessory male sex glands in the penile urethra has been demonstrated by prostatic-specific antigen in cells of these cysts with the help of immunohistochemistry. ${ }^{12}$

The cysts are usually small, about $1 \mathrm{~cm}$ in diameter. They occur on the lateral margin of the urethral meatus and, at times, can be bilateral. They may be congenital or they may appear spontaneously. ${ }^{9}$ In our case, the lesion was congenital and about $0.9 \mathrm{~cm}$ in diameter and appeared spontaneously. However, sometimes, they may cause urinary retention, painful micturition, painful intercourse, ${ }^{13}$ poor cosmesis, and distortion of urinary stream. When the cysts are traumatized, they may bleed, rupture, or become infected. In our case, the patient was unmarried with no history of sexual intercourse, trauma, previous surgery, or infections. The patient did complain of penile curvature during erection, spraying of the downward urinary stream, and poor cosmesis. One of the most important parts of the lesions was present in the patient since his birth. Although cases of urethral duplication and penile hypospadias with chordee cases have been reported, we did not find a parameatal cyst in our patient. Also in our case the urethral duplication was similar to the Effmann Type I classification, but the localization was more proximally.

\section{Conclusion}

We report for the first time a different variation of urethral duplication accompanied by mid-penile hypospadias, penile chordee, and parameatal cyst; moreover, we believe that the etiology of the these anomalies is the abnormal Mullerian duct termination. In spite of the numerous theories recommended to describe these anomalies, no single theory explains all the various types of anomalies. More research is needed. 


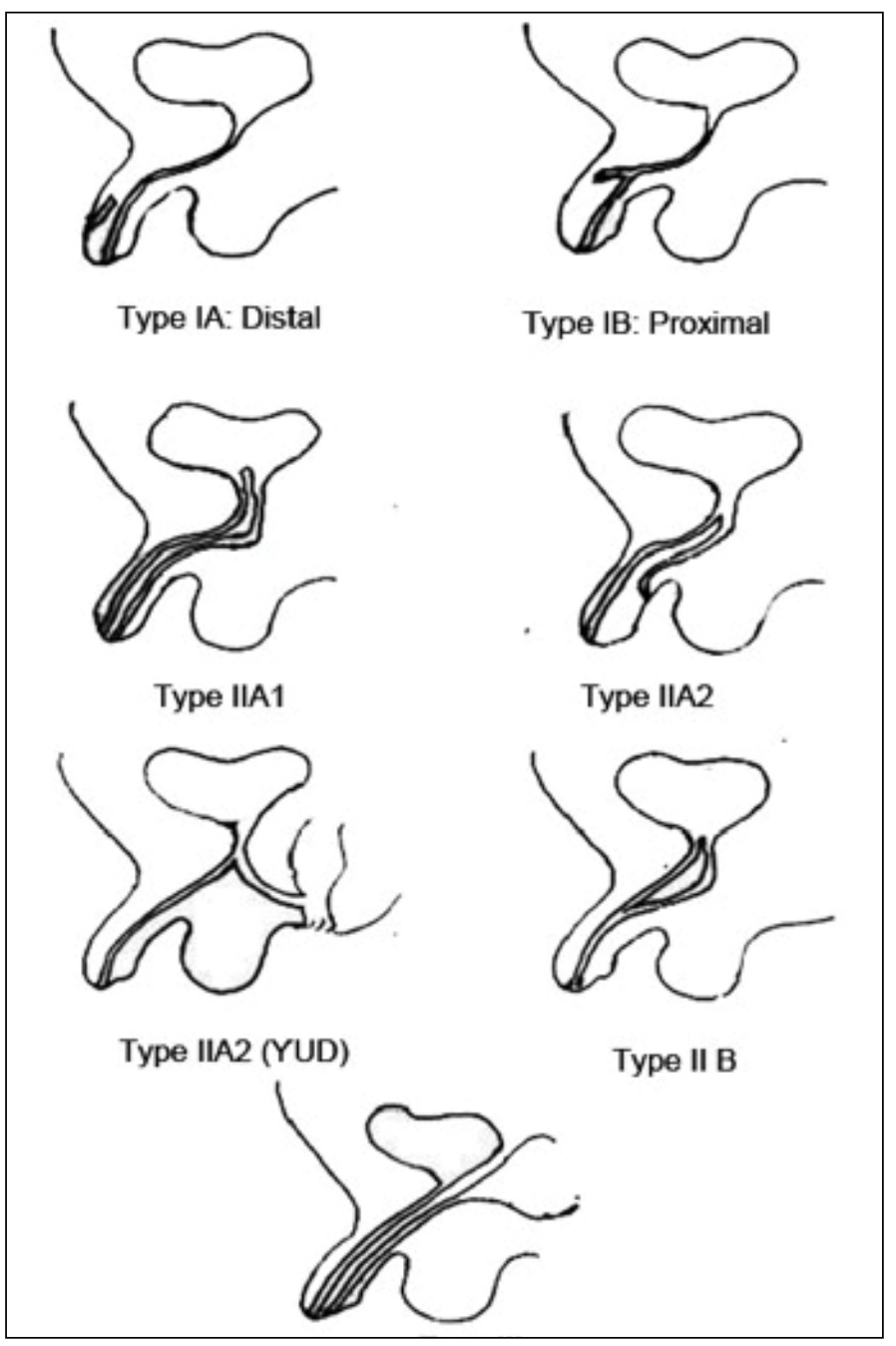

Fig. 2. Illustration of Effman classification.

Competing interests: The authors declare no competing financial or personal interests.

This paper has been peer-reviewed.

\section{References}

1. Levin TL, Han B, Little BP. Congenital anomalies of the male urethra. Pediatr Radiol 2007;37:851-62. http://dx.doi.org/10.1007/s00247-007-0495-0

2. Woodhouse CR, Williams DI. Duplication of the lower urinary tract in children. Br J Urol 1979;51:481-7. http://dx.doi.org/10.1111/j.1464-410X.1979.tb03583.x

3. Vijayaraghavan SN, Nirmala AB. Complete duplication of urinary bladder and urethra: Prenatal sonographic features. Ultrasound Obstet Gynecol 2004;24:464-6. http://dx.doi.org/10.1002/uog.1093

4. Casselman J, Williams DI. Duplication of the urethra. Acta Urol Belg 1996;34:535-41.

5. Das S, Brosman SA. Duplication of the male urethra. J Urol 1977;117:452-4.

6. Rice PE, Holder TM, Ashcraft KW. Congenital posterior urethral perineal fistula: A case report. J Urol 1978;199:416-7.

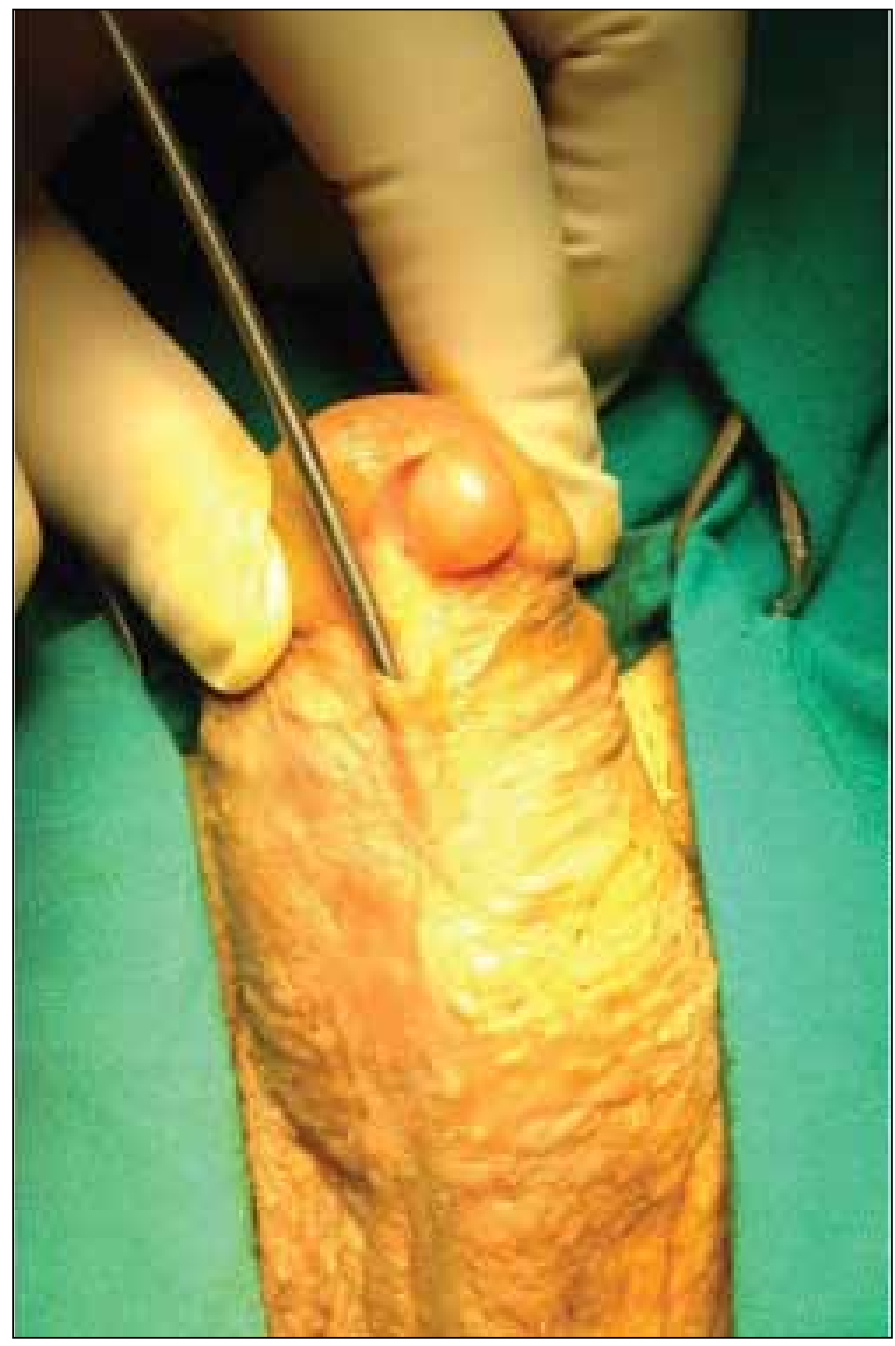

Fig. 3. Examination under anesthesia: Open urethra and parameatal cyst.

7. Effmann EL, Lebowitz RL, Colodny AH. Duplication of the urethra. Radiology 1976;119:179-85. http:// dx.doi.org/10.1148/119.1.179

8. Thompson IM, Lantin PM. Parameatal cyst of the glans penis. J Urol 1956;76:753-5.

9. Yoshida K, Nakame Y, Negishi T. Parameatal urethral cysts. Urology 1985;36:490-1. http://dx.doi. org/10.1016/0090-4295(85)90162-1

10. Hill JT, Ashken MH. Parameatal urethral cyst: A review of six cases. Br J Urol 1977;49:323-5. http:// dx.doi.org/10.1111/i.1464-410X.1977.tb04146.x

11. Soyer T, Aydemir E, Atmaca E. Paraurethral cysts in female newborns: Role of maternal estrogenes. J Ped Adol Gyn 2007;20:249-51. http://dx.doi.org/10.1016/i.jpag.2007.04.007

12. Ichiyanagi N, Shibata T, Matsumura T, et al. Immunohistochemical identification of prostatic -specific antigen in parameatal urethral cysts of the glans penis. Br J Urol 1998;81:170-1. http://dx.doi. org/10.1046/i.1464-410x.1998.00353.x

13. Nerli RB, Patil S, Hiremath MB. Parameatal urethral cyst presenting with painful intercourse. Med Surg Urol 2012;1:104.

Correspondence: Dr. Devrim Tuglu, Kirikkale University Tip Fakultesi, Uroloji AD, Yahsihan, 71100, Kirikkale, Turkey; devrimtuglu@gmail.com 